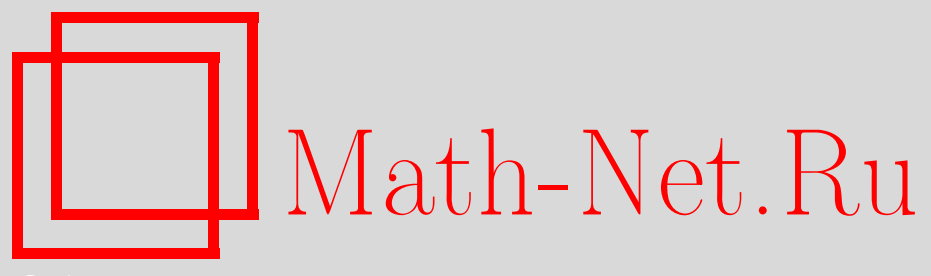

Ф. А. Богомолов, Вик. С. Куликов, Ю. И. Манин, В. В. Никулин, Д. О. Орлов, А. Н. Паршин, Ю. Г. Прохоров, А. В. Пухликов, М. Рид, И. Р. Шафаревич, В. В. Шокуров, Василий Алексеевич Исковских (некролог), УМН, 2009, том 64, выпуск 5, 167-174

DOI: https://doi.org/10.4213/rm9304

Использование Общероссийского математического портала Math-Net.Ru подразумевает, что вы прочитали и согласны с пользовательским соглашением http: //www . mathnet.ru/rus/agreement

Параметры загрузки:

IP: 35.173 .219 .149

26 апреля 2023 г., 16:46:54

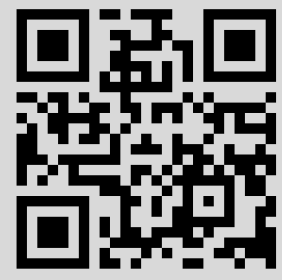




\section{Василий Алексеевич Исковских}

4 января 2009 г. трагически оборвалась жизнь выдающегося русского ученого-математика, члена-корреспондента Российской академии наук Василия Алексеевича Исковских.

Василий Алексеевич родился 2 мая 1939 г. в селе Рождественка Шарлыкского района Оренбургской области в крестьянской семье. Однако его рождение было зарегистрировано лишь 1 июля 1939 г., что и стало его официальным днем рождения. В 1958 г. он поступил на физико-математический факультет Ташкентского государственного университета. В 1963 г. ему, как сильнейшему студенту своего курса, была предложена возможность продолжить образование на механико-математическом факультете Московского государственного университета.

В Москве Василий Исковских сразу становится активным участником семинара профессора И. Р. Шафаревича. На этом семинаре тогда еще

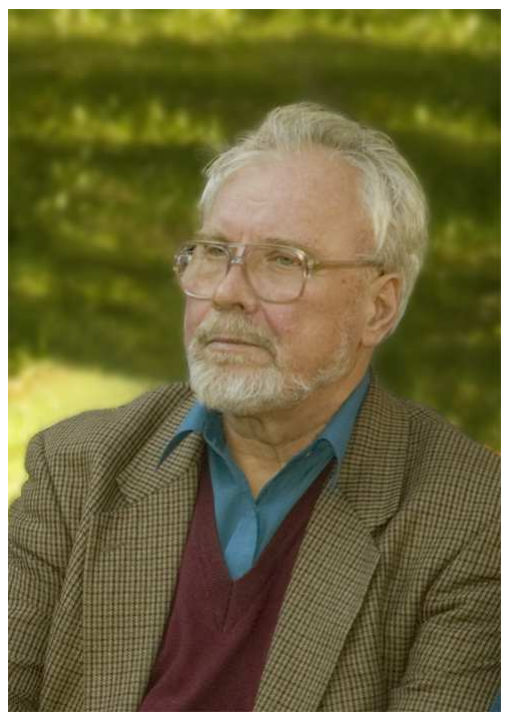
совсем молодая московская школа алгебраической геометрии делала первые шаги, определяя направления будущего развития и формируя собственный стиль изучения проблем алгебраической геометрии. Под руководством своего учителя, профессора Ю.И. Манина, выбрал себе область исследований и В.А. Исковских: бирациональную геометрию алгебраических многообразий, близких к рациональным. Закончив в 1964 г. с отличием механико-математический факультет МГУ, он поступает в 1965 г. к профессору Ю. И. Манину в аспирантуру.

60-е годы были периодом становления как созданной и руководимой профессором И. Р. Шафаревичем московской алгебро-геометрической школы, так и современной алгебраической геометрии в целом. В первую очередь необходимо было с помощью современной техники восстановить достижения классической итальянской школы, переосмыслить на новом уровне результаты итальянских классиков, исправить их ошибки, восполнить пробелы и устранить неточности в их доказательствах. Речь шла, прежде всего, о построении систематической теории алгебраических поверхностей [79], одним из наиболее важных разделов которой является теория рациональных поверхностей, обладающих богатой бирациональной геометрией. В.А.Исковских принадлежал к плеяде наиболее ярких представителей первого поколения московской школы алгебраической геометрии, таких, как Ю. И. Манин, Б. Г. Мойшезон, Г. Н. Тюрина и А.Н. Тюрин.

Основополагающие теоремы о бирациональной геометрии поверхностей над незамкнутыми полями были доказаны Ю. И. Маниным. Продолжая его исследования, 
В. А. Исковских получил первые важные результаты о бирациональном типе рациональных поверхностей с пучком рациональных кривых [1]-[3], составившие содержание его кандидатской диссертации (1968 г.). Работы Ю. И. Манина и В. А. Исковских по теории рациональных поверхностей над незамкнутыми полями открыли современный этап в бирациональной геометрии. Оглядываясь назад, в этих работах 60 -х годов легко распознать прообразы многих достижений современной многомерной алгебраической геометрии. В своих самых последних работах В.А. Исковских (совместно с И.В. Долгачевым) снова возвращается к бирациональной геометрии алгебраических поверхностей [64], [65].

Отсчет современной теории трехмерных алгебраических многообразий можно вести с того момента, когда была отрицательно решена проблема Люрота: всякое ли унирациональное многообразие рационально? (На алгебраическом языке: всякое ли подполе поля рациональных функций $k\left(t_{1}, \ldots, t_{n}\right)$ есть чисто трансцендентное расширение поля констант $k$, т. е. изоморфно $k\left(s_{1}, \ldots, s_{m}\right)$ ?) В размерностях 1 (над произвольным полем) и 2 (над алгебраически замкнутым полем) положительный ответ дают классические теоремы, однако для понимания трехмерной задачи требуются существенно более продвинутые методы. Решение было получено в 1970 г. независимо В.А. Исковских и Ю.И. Маниным [5], М. Артином и Д. Мамфордом в [67] с использованием группы Брауэра, всегда интересовавшей В. А. Исковских [12], [13], и Г. Клеменсом и Ф. Гриффитсом в известной работе о промежуточном якобиане [68]. Методы и контрпримеры этих работ абсолютно независимы и совершенно различны.

Однако к концу 80-х годов прошлого столетия стало ясно, что в статье [5] (ссылки на которую можно найти едва ли не в каждой работе наших дней по бирациональной геометрии) было сделано гораздо больше, чем просто доказана нерациональность трехмерных квартик в $\mathbb{P}^{4}$. Опираясь на идеи классиков, прежде всего - М. Нётера и Дж. Фано, В.А. Исковских и Ю. И. Манин построили современный эффективный метод (“метод максимальных особенностей”), позволяющий исчерпывающим образом описывать бирациональные отображения широкого класса многообразий близких к рациональным. До сих пор трехмерная квартика является пробным камнем всех новых концепций и технических методов в бирациональной геометрии.

После 1971 г. В. А. Исковских с успехом применил метод максимальных особенностей к изучению бирациональных отображений нескольких классов многообразий Фано - двойных квартик индекса 1 , полного пересечения квадрики и кубики в $\mathbb{P}^{5}$, двойного конуса Веронезе. Эти результаты особенно важны потому, что они наметили общие контуры бирациональной классификации в размерности три и выше [9], [10], [19]. В частности, достигнутый В.А. Исковских прогресс в сочетании с глубоким пониманием двумерной бирациональной геометрии над незамкнутыми полями позволил ему в конце 70-х сформулировать гипотезу о единственности структуры расслоения на коники при достаточно больших вырождениях. Она была вскоре доказана его учеником В. Г. Саркисовым [85], [86]. Десять лет спустя Василий Алексеевич формулирует аналогичную гипотезу для трехмерных многообразий с пучком поверхностей дель Пеццо [44]. Эта гипотеза будет доказана А. В. Пухликовым в 1996 г. [80].

В целом сорок лет исследований, начатых фундаментальной работой В.А. Исковских и Ю.И. Манина о трехмерных квартиках, превратили трехмерную бирациональную геометрию в глубокую и систематическую теорию. Основным объектом этой теории является расслоение Мори $\pi: V \rightarrow S$, где база $S$ есть либо точка (и тогда многообразие $V$ есть $\mathbb{Q}$-многообразие Фано), либо прямая $\mathbb{P}^{1}$ (и тогда $V$ есть многообразие с пучком поверхностей дель Пеццо), либо рациональная поверхность (и тогда $V / S$ есть Мори-расслоение на коники). Для, в некотором смысле, "большинства" расслоений Мори $V / S$ любое бирациональное отображение $V \rightarrow V^{\prime}$, где $V^{\prime} / S^{\prime}$ - произвольное расслоение Мори, является послойным относительно заданных 
структур расслоения. Этот феномен называется бирациональной жесткостью. Первым примером бирационального жесткого многообразия была трехмерная квартика В. А. Исковских и Ю. И. Манина [5]. Подобное явление имеет место и в произвольной размерности (см. [81]-[83]). В размерности три, которая, начиная с 1970 г. и вплоть до последних его работ, была, наряду с поверхностями, основным предметом научных интересов В. А. Исковских, сейчас имеются наиболее полные результаты о бирациональной жесткости: доказана программа Саркисова о факторизации бирациональных отображений между расслоениями Мори в цепочку элементарных линков [69] (в настоящее время существование подобного разложения известно в любой размерности), полностью изучен вопрос о бирациональной жесткости для взвешенных гиперповерхностей Фано [70], получены близкие к окончательным результаты о многообразиях с пучком поверхностей дель Пеццо [80], [84], теорема Саркисова [85] решает вопрос о бирациональной жесткости для "почти всех" расслоений на коники. Фронт исследований по этой тематике продвинулся очень далеко вперед по сравнению с началом 70-х годов - но тем ярче видится важность первого прорыва и глубже понимается его значение.

Следует также отметить, что метод максимальных особенностей Исковских-Манина идейно связан с понятиями логканонического порога и соответствующего идеала, которые играют ключевую роль в современных исследованиях. Доказательство теоремы о квартике неоднократно переосмысливалось на основе современных методов [70], в том числе и самим Василием Алексеевичем [52]. Его современные версии короче и проще. Однако общий подход остается тем же самым и в рассуждениях недавних работ реализуется по существу та же логика, которая позволила почти 40 лет назад осуществить один из наиболее впечатляющих прорывов в алгебраической геометрии ХХ столетия.

Другим важным направлением исследований В.А. Исковских, существенно повлиявшим на развитие многомерной алгебраической геометрии была бирегулярная классификация трехмерных многообразий Фано. Отметим, что само понятие многообразия Фано принадлежит Исковских, который по своей скромности иногда даже сомневался в его важности вплоть до конца 70-х годов. Этот класс многообразий существенно отличается даже в трехмерном случае от класса многообразий, рассматриваемых самим Фано, - неособые проективные подмногообразия с каноническими кривыми-сечениями [71]-[73]. Однако, как показало время, многообразия Фано исключительно важны как в контексте общей проблемы классификации алгебраических многообразий, так и для многих задач алгебраической и арифметической геометрии и математической физики. В начале 70-х систематическое исследование трехмерных многообразий еще не было начато, имелись лишь разрозненные результаты, так что работы [11], [14], [18] были в полном смысле пионерскими. В. А. Исковских дал строгое обоснование метода двойной проекции, что позволило ему (в предположениях существования гладкого антиканонического дивизора и прямой на многообразиях Фано) предъявить полный список многообразий Фано с группой Пикара $\mathbb{Z}$. Эти предположения были вскоре были доказаны В. В. Шокуровым [68], [69]. Условие цикличности группы Пикара предполагалось и Фано, а в современной геометрии оно приводит к многообразиям Мори-Фано - объектам категории Мори. Как и всякий классик науки, В. А. Исковских допустил неточность в классификации, пропустив (всего лишь одно) многообразие в семействе, которое было добавлено С. Мукаи и Х. Умемурой [77]. Полученная классификация была мощным прорывом в совершенно новую область. Успехи теории Мори в 80-е годы были в значительной мере подготовлены выдающимися результатами В. А. Исковских о трехмерных многообразиях Фано. В окончательном виде эта теория была опубликована в монографии [31]. Результаты по бирегулярной и бирациональной геометрии трехмерных многообразий состави- 
ли предмет его докторской диссертации “Трехмерные алгебраические многообразия, близкие к рациональным" (1979 г.).

В цикле работ [36], [38], [40], [42], [43], совместных с Ф.К. Кабдыкаировым и С. Л. Трегубом, продолжавших исследования 1960-х годов [1], [2] и публиковавшихся вплоть до недавнего времени [47], Василий Алексеевич построил исчерпывающую теорию бирациональных отображений рациональных поверхностей над незамкнутыми полями в терминах категории Мори и линков. В последние годы эти результаты нашли приложение при завершении классификации конечных подгрупп группы Кремоны плоскости [64], начатой Кантором и Виманом в конце 19-го века [75], [78], а также при ответе на вопрос Серра о порядках циклических подгрупп над полем рациональных чисел [65]. Эти последние работы В. А. Исковских (совместные с И. В. Долгачевым) были признаны одними из лучших по Академии наук в 2008 г.

Однако основным направлением исследований, которые проводит В. А. Исковских начиная с середины 80-х годов, является проблема рациональности трехмерных расслоений на коники [21], [29], [37], [39], [46]. Эта проблема является одной из ключевых для современной бирациональной геометрии. Исходя из гипотезы Шокурова о необходимом условии рациональности [70] и известных примеров, когда этого условия не достаточно, В. А. Исковских сформулировал геометрический критерий рациональности в терминах расслоения на коники. Он показал, что его формулировка критерия рациональности влечет решение классической проблемы Кантора о конгруэнции рациональных кривых в $\mathbb{P}^{3}$ (1901 г.). Более того, он свел решение проблемы к вопросу о каноничности особенности базы расслоения на коники с терминальными особенностями (гипотеза Исковских) с точностью до ограниченного семейства расслоений на коники [46]. Этот вопрос был недавно положительно решен С. Мори и Ю. Г. Прохоровым [76]. Поэтому гипотетический критерий рациональности по существу сведен к перебору ограниченного числа семейств (т. е. семейств с конечным числом параметров), где возможны новые исключения и новые методы. Однако этим уже будет заниматься новое поколение геометров.

Научные идеи и результаты В.А. Исковских оказали большое влияние на исследования алгебраических геометров всего мира. В 1983 г. он был приглашенным докладчиком на Международном математическом конгрессе в Варшаве. Работы Василия Алексеевича даже тридцатилетней давности продолжают привлекать внимание, широко обсуждаются. Его контрпример к принципу Хассе для системы двух квадратичных форм от пяти переменных активно изучался и получил развитие в серии работ Кольо-Телена, Сансука и других. Что же касается работ по бирегулярной и бирациональной геометрии многообразий Фано, то они справедливо считаются классическими. Эти работы, например, оказали значительное влияние на оксфордскую школу [74].

Василий Алексеевич был не только выдающимся ученым, но и замечательным педагогом. Более тридцати лет на мехмате МГУ продолжался его семинар "Геометрия алгебраических многообразий”. Самостоятельная научная работа десятков молодых математиков начиналась с участия в этом семинаре. Василий Алексеевич также руководил семинарами по теории чисел на мехмате МГУ и в МИАНе. Для многих основой алгебро-геометрического образования стали прочитанные им курсы лекций по самой разнообразной тематике (алгебраические кривые и их якобианы, геометрия многообразий Фано, проблемы рациональности, теория Мори и многие, многие другие).

Перечислим список учеников Василия Алексеевича, подготовивших и защитивших под его руководством кандидатские диссертации: В. А. Алексеев, В. В. Батырев, А. А. Борисов (совм. с Ю. Г. Зархиным), Л. А. Борисов (совм. с И. В. Долгачевым), С. С. Галкин, М. М. Гриненко, Н.П. Гушель, И. В. Дёмин, А. А. Загорский, 
Н. Ф. Зак (совм. с Ю. Г. Прохоровым), А. И. Илиев, Ф. К. Кабдыкаиров, В. И. Канев (совм. с А. Тодоровым) Л. Кацарков, С. А. Кудрявцев, С. М. Львовский, Д. Г. Маркушевич, Д. А. Мельников, В. К. Нгуен (совм. с А. Н. Паршиным), Д. О. Орлов (совм. с А. И. Бондалом), Ю. М. Полякова, В. В. Пржиялковский (совм. с В. В. Голышевым), Ю.Г. Прохоров, А. В. Пухликов, С. Ю. Рыбаков (совм. с М. А. Цфасманом), В.Г. Саркисов, И.В. Соболев (совм. с А.В. Пухликовым), Д. А. Степанов (совм. с Ю. Г. Прохоровым), С. Л. Трегуб, И. Ю. Фёдоров, Т. Фиммель (совм. с А. Н. Паршиным), С. И. Хашин, И. А. Чельцов (совм. с В. В. Шокуровым), К. А. Шрамов (совм. с Ю. Г. Прохоровым), С. Ю. Эндрюшка. Отметим, что в 90-е годы, особенно трудные для российской науки в целом и математики в частности, когда проблема преемственности и притока молодых исследователей стояла исключительно остро, на семинарах профессора В. А. Исковских продолжалась активная научная жизнь, новые студенты и аспиранты включались в научную работу. Редкая работоспособность и энтузиазм Василия Алексеевича проявились в участии в редколлегиях ведущих математических журналов, экспертном совете ВАК, в заседаниях ученых советов и организации десятков научных школ и конференций. С особым вниманием и заботой Василий Алексеевич относился к организации школ по алгебраической геометрии в Ярославле.

За выдающийся вклад в науку В. А. Исковских в 2008 г. был избран членом-корреспондентом РАН. С 2002 г. он являлся почетным доктором Туринского университета, в котором когда-то работал Джино Фано.

Жизнь В.А. Исковских явилась достойным примером самоотверженного служения отечественной науке. Светлую память о Василии Алексеевиче навсегда сохранят наши сердца.

P.S. C 29 июня по 3 июля 2009 г. в Математическом институте им. В. А. Стеклова Российской академии наук прошла Международная конференция "Геометрия алгебраических многообразий”, посвященная памяти Василия Алексеевича Исковских. 1 июля Василию Алексеевичу исполнилось бы 70 лет. Организаторы планировали приурочить данную конференцию к этому юбилею, но по трагическому стечению обстоятельств жизнь Василия Алексеевича оборвалась за полгода до знаменательной даты. Организаторы решили провести конференцию в память о выдающемся ученом.

Приглашенными докладчиками были известные математики из разных стран: В. А. Алексеев, К. Биркар, И. А. Чельцов, М. Кавакита, Д. Б. Каледин, В. Канев, Л. Кацарков, А. Корти, В. С. Куликов, А. Г. Кузнецов, Дж. Мак-Кернан, Ш. Мори, Ш. Мукаи, В.В. Никулин, А.Н. Паршин, В.Л. Попов, А. В. Пухликов, М. Рид, А.Н. Скоробогатов, К.А. Шрамов. В организационный и программный комитеты входили Ю. И. Манин, Ш. Мори, Д. О. Орлов, В. В. Пржиялковский, Ю. Г. Прохоров и В. В. Шокуров.

Конференция ярко продемонстрировала, что научные направления, которыми занимался В.А. Исковских, являются одними из центральных в современной алгебраической геометрии. Многие новые достижения, представленные в выступлениях докладчиков, непосредственно основывались на классических результатах Василия Алексеевича.

Кроме того, в начале 2009 г. вышел том Трудов Математического института им. В.А. Стеклова "Многомерная алгебраическая геометрия", посвященный памяти члена-корреспондента РАН В.А. Исковских, со статьями его друзей, коллег и учеников.

Ф. А. Богомолов, Вик. С. Куликов, Ю.И. Манин, В.В. Никулин, Д. О. Орлов, А.Н. Паршин, Ю. Г. Прохоров, А. В. Пухликов, М. Рид, И.Р. Шафаревич, В.В. Шокуров 


\section{Список основных печатных работ В. А. Исковских}

[54] В.А. Исковских, "О бирациональной жесткости гиперповерхностей степени $N$ в $\mathbb{P}^{N}$ ", Труды сем. И. Р. Шафаревича, 2 (2000), 67-81.

[55] В. А. Исковских, "Бирациональная жесткость гиперповерхностей Фано в рамках теории Мори", УМН, 56:2 (2001), 3-86; англ. пер.: V. A. Iskovskikh, "Birational rigidity of Fano hypersurfaces in the framework of Mori theory", Russian Math. Surveys, 56:2 (2001), 207-291.

[56] В.А. Исковских, " $b$-Дивизоры и функциональные алгебры по Шокурову", Тр. МИАН, 240, Наука, М., 2003, 8-20; англ. пер.: V. A. Iskovskikh, "b-divisors and functional algebras according to Shokurov", Proc. Steklov Inst. Math., 240 (2003), $4-15$.

[57] В.А. Исковских, "О работе Шокурова 'Prelimiting flips"”, Бирациональная геометрия: линейные системы и конечно порожденные алгебры, Тр. МИАН, 240, Наука, M., 2003, 21-42; англ. пер.: V.A. Iskovskikh, "On Shokurov's paper "Prelimiting flips"", Proc. Steklov Inst. Math., 240 (2003), 16-36.

[58] В. А. Исковских, “Два несопряженных вложения группы $S_{3} \times \mathbb{Z}_{2}$ в группу Кремоны”, Теория чисел, алгебра и алгебрачческая геометрия, Тр. МИАН, 241, Наука, M., 2003, 105-109; англ. пер.: V. A. Iskovskikh, "Two nonconjugate embeddings of the group $S_{3} \times Z_{2}$ into the Cremona group", Proc. Steklov Inst. Math., 241 (2003), 93-97.

[59] V.A. Iskovskikh, "On the Noether-Fano inequalities", The Fano Conference, Univ. Torino, Turin, 2004, 25-35.

[60] В. А. Исковских, "О факторизации бирациональных отображений”, Чебышевский сборник, 5:4(12) (2004), 21-34.

[61] В. А. Исковских, В. В. Шокуров, "Бирациональные модели и перестройки”, УМН, 60:1 (2005), 29-98; англ. пер.: V. A. Iskovskikh, V. V. Shokurov, "Birational models and flips", Russian Math. Surveys, 60:1 (2005), 27-94.

[62] V.A. Iskovskikh, "On finite subgroups of the Cremona group", Vietnam J. Math., 33: Special Issue (2005), 61-80.

[63] В.А. Исковских, "Факторизация бирациональных отображений рациональных $G$-поверхностей”, Труды IV Колмогоровских чтений, Изд. ЯГПУ, Ярославль, 2006, 38-45.

[64] I. V. Dolgachev, V.A. Iskovskikh, "Finite subgroups of the plane Cremona group", Algebra, arithmetic, and geometry Vol. I: In Honor of Yu. I. Manin, Progr. Math., 269, eds. Yu. Tschinkel, Yu. Zarhin, Birkhäuser, 2009; arXiv : math/0610595v1, 2006.

[65] I. V. Dolgachev, V. A. Iskovskikh, "On elements of prime order in the plane Cremona group over a perfect field", Int. Math. Res. Not., 2009, 3467-3485,; arXiv: 0707.4305, 2007.

[66] V.A. Iskovskikh, "Two non-conjugate embeddings of $S_{3} \times \mathbb{Z}_{2}$ into the Cremona group. II", Algebraic geometry in East Asia (Hanoi, 2005), Adv. Stud. Pure Math., 50, Math. Soc. Japan, Tokyo, 2008, 251-267.

\section{Цитируемые работы других авторов}

[67] M. Artin, D. Mumford, "Some elementary examples of unirational varieties which are not rational", Proc. London Math. Soc. (3), 25:1 (1972), 75-95.

Начало списка см.: УМН, 54:4 (1999), 185-187. 
[68] C. H. Clemens, P. A. Griffiths, "The intermediate Jacobian of the cubic threefold", Ann. of Math. (2), 95 (1972), 281-356.

[69] A. Corti, "Factoring birational maps of threefolds after Sarkisov", J. Algebraic Geom., 4:2 (1995), 223-254.

[70] A. Corti, A. Pukhlikov, M. Reid, "Fano 3-fold hypersurfaces", Explicit birational geometry of 3-folds, London Math. Soc. Lecture Note Ser., 281, Cambridge Univ. Press, Cambridge, 2000, 175-258.

[71] G. Fano, "Sulle varietà algebriche a tre dimensioni a curve-sezioni canoniche", Mem. Accad. Ital., 8 (1937), 23-64.

[72] G. Fano, "Sulle varietà algebriche a tre dimensioni aventi tutti i generi nulli", Atti Congresso Bologna, 4 (1931), 115-121.

[73] G. Fano, "Nuove ricerche sulle varietà algebriche a tre dimensioni a curve-sezioni canoniche", Pont. Acad. Sci. Comment., 11 (1947), 635-720.

[74] N. J. Hitchin, "Kählerian twistor spaces", Proc. London Math. Soc. (3), 43:1 (1981), 133-150.

[75] S. Kantor, Theorie der endlichen Gruppen von eindeutigen Transformationen in der Ebene, Mayer \& Müller, Berlin, 1895.

[76] S. Mori, Y. Prokhorov, "On $\mathbb{Q}$-conic bundles", Publ. Res. Inst. Math. Sci., 44:2 (2008), 315-369.

[77] S. Mukai, H. Umemura, "Minimal rational threefolds", Algebraic geometry: Proceedings of the Japan-France Conference (Tokyo/Kyoto, October, 5-14, 1982), Lecture Notes in Math., 1016, Springer, Berlin, 1983, 490-518.

[78] A. Wiman, "Zur Theorie der endlichen Gruppen von birationalen Transformationen in der Ebene", Math. Ann., 48:1-2 (1896), 195-240.

[79] И. Р. Шафаревич, Б. Г. Авербух, Ю. К. Вайнберг, А. Б. Жижченко, Ю. И. Манин, Б. Г. Мойшезон, Г. Н. Тюрина, А.Н. Тюрин, “Алгебраические поверхности”, Тр. МИАН, 75, Наука, М., 1965, 1-215.

[80] А.В. Пухликов, "Бирациональные автоморфизмы трехмерных алгебраических многообразий с пучком поверхностей дель Пеццо", Изв. РАН. Сер. матем., 62:1 (1998), 123-164; англ. пер.: A. V. Pukhlikov, "Birational automorphisms of algebraic threefolds with a pencil of Del Pezzo surfaces", Izv. Math., 62:1 (1998), 115-155.

[81] A. V. Pukhlikov, "Birational automorphisms of Fano hypersurfaces", Invent. Math., 134:2 (1998), 401-426.

[82] A. V. Pukhlikov, "Birationally rigid Fano complete intersections", J. Reine Angew. Math., 541 (2001), 55-79.

[83] А.В. Пухликов, "Бирационально жесткие многообразия. І. Многообразия Фано", УМН, 62:5 (2007), 15-106; англ. пер.: A. V. Pukhlikov, "Birationally rigid varieties. I. Fano varieties", Russian Math. Surveys, 62:5 (2007), 857-942.

[84] М. М. Гриненко, "Расслоения на поверхности дель Пеццо", УМН, 61:2 (2006), 67-112; англ. пер.: M. M. Grinenko, "Fibrations into del Pezzo surfaces", Russian Math. Surveys, 61:2 (2007), 255-300.

[85] В.Г. Саркисов, "Бирациональные изоморфизмы расслоений коник", Изв. АН СССР. Сер. матем., 44:4 (1980), 918-944; англ. пер.: V. G. Sarkisov, "Birational automorphisms of conic bundles", Math. USSR-Izv., 17:1 (1981), 177-202.

[86] В. Г. Саркисов, "О структурах расслоений на коники”, Изв. АН СССР. Сер. матем., 46:2 (1982), 371-408; англ. пер.: V. G. Sarkisov, "On conic bundle structures", Math. USSR-Izv., 20:2 (1983), 355-380. 
[87] В. В. Шокуров, "Гладкость общего антиканонического дивизора на многообразии Фано", Изв. АН СССР. Сер. матем., 43:2 (1979), 430-441; англ. пер.: V.V. Šokurov, "Smoothness of the general anticanonical divisor on a Fano 3-fold", Math. USSR-Izv., 14:2 (1980), 395-405.

[88] В. В. Шокуров, "Существование прямой на многообразиях Фано”, Изв. АН СССР. Сер. матем., 43:4 (1979), 922-964; англ. пер.: V. V. Šokurov, "The existence of a straight line on Fano 3-folds", Math. USSR-Izv., 15:1 (1980), 173-209.

[89] В.В. Шокуров, "Многообразия Прима: теория и приложения", Изв. АН СССР. Сер. матем., 47:4 (1983), 785-855; англ. пер.: V. V. Shokurov, "Prym varieties: theory and applications", Math. USSR-Izv., 23:1 (1984), 83-147. 